EGU21-16477, updated on 02 Aug 2021

https://doi.org/10.5194/egusphere-egu21-16477

EGU General Assembly 2021

(c) Author(s) 2021. This work is distributed under

the Creative Commons Attribution 4.0 License.

\title{
Soils training and research: Who's legacy?
}

\author{
Malika Mezeli ${ }^{1}$, Daniel Evans ${ }^{2}$, Davey Jones ${ }^{3}$, Olivia Lawrenson ${ }^{1}$, and Philip Haygarth ${ }^{1}$ \\ ${ }^{1}$ Lancaster Environment Centre, Lancaster University, UK \\ ${ }^{2}$ School of Water, Energy and Environment, Cranfield University, UK \\ ${ }^{3}$ Environment Centre Wales, Bangor University, UK
}

Soils Training and Research Studentships (STARS) is a NERC and BBSRC funded Centre for Doctoral Training (CDT). The consortium comprises of four universities and four research institutes from around England, Scotland and Wales who are collaborating to offer training to PhD students in soil science. The program offered forty PhD studentships over four cohorts, which started in 2016 and due to complete in 2022. The ambitious program aimed to address the under representation of soil science and graduates in UK higher education institutes.

The comprehensive CDT supports cross-institute participation which allows a sharing of resources both human and physical promoting a cross-disciplinary research environment. Students have received group training from experts across the respective establishments encouraging interinstitute collaboration and support. Centralised funding has supported a range of outside training from motion graphic skills to clowning in public to genomics and statistics and the production of video media products by students and staff communicating their research and knowledge. In addition, the managerial structure at STARS has allowed for easy access to professional and industry placements for students. By building upon the traditional PhD experience, STARS has been able to facilitate not only quality doctoral research but also graduates with the skill set and networks required by the next generation of soils scientists to help achieve the 2030 Sustainable Development Goals.

Collectively, the STARS consortium has amassed a vast range of soils research, knowledge, skills and training resources. To remain ambitious and forward focused our legacy project will bring together these resources and continue to work to build on the relationships forged under STARS and into the broader soil community. These resources will be accessible to those outside of STARS and outside of the research community because resources that offer the tools to support healthy soils, clean water, access to healthy food is not our legacy, it is everyone's. The legacy we are left with will not only be comprised of our journal publications but our success in sharing our knowledge, translating our findings and being active participants in global dialogues. 